08,09

\title{
Фотолюминесценция композиций полиметилметакрилат/(Zn, Cu, Ag)S : $\mathrm{Eu}^{3+}$
}

\author{
( В.П. Смагин, Л.В. Затонская, Е.Г. Ильина, Е.П. Харнутова
}

Алтайский государственный университет, Барнаул, Россия

E-mail: smaginV@yandex.ru

Поступила в Редакцию 19 февраля 2020 г.

В окончательной редакции 19 февраля 2020 г.

Принята к публикации 11 марта 2020 г.

Люминесцирующие наноразмерные частицы (квантовые точки, КТ) ( $\mathrm{Zn}, \mathrm{Cu}, \mathrm{Ag}) \mathrm{S}: \mathrm{Eu}^{3+}$ синтезированы при разложении тиоацетамидных комплексов металлов в среде метилметакрилата в процессе блочной полимеризации при нагревании. Образование КТ подтверждено соответствующей им полосой в оптическом спектре поглощения полимерных композиций. Фотолюминесценция композиций ПММА/( $\mathrm{Zn}, \mathrm{Cu}, \mathrm{Ag}) \mathrm{S}: \mathrm{Eu}^{3+}$ проявляется в виде сложной полосы, связанной с дефектами кристаллической структуры, сформировавшимися при легировании $\mathrm{ZnS}$ ионами меди и серебра, и набора узких полос люминесценции ионов $\mathrm{Eu}^{3+}$. Возбуждение люминесценции происходит в результате межзонного перехода и переходов электронов из валентной зоны на уровни дефектов $\mathrm{ZnS}$, и собственного поглощения энергии ионами $\mathrm{Eu}^{3+}$. Связь ионов $\mathrm{Eu}^{3+}$ с частицами $\mathrm{ZnS}$ подтверждена зависимостью интенсивности широкополосной люминесценции $\mathrm{ZnS}$ от концентрации ионов $\mathrm{Eu}^{3+}$ и увеличением интенсивности узкополосной люминесценции ионов $\mathrm{Eu}^{3+} \mathrm{B}$ результате переноса энергии с уровней легированных кристаллов $\mathrm{ZnS}$ на уровни энергии ионов $\mathrm{Eu}^{3+}$.

Ключевые слова: сульфид цинка, легирование, ионы металлов, европий, фотолюминесценция, полиметилметакрилат, композиции.

DOI: 10.21883/FTT.2020.07.49476.037

\section{1. Введение}

Сульфид цинка является одним из наиболее изученных и востребованных промышленностью люминофоров [1,2]. Порошки, пленки, коллоидные растворы $\mathrm{ZnS}$ находят применение в оптике, электронике, медицине [3]. Спектр люминесценции объемных кристаллов $\mathrm{ZnS}$ состоит из набора полос, расположенных в видимой области спектра. Он зависит от способа получения, состава и структуры образцов, условий возбуждения и других факторов. Изменяя степень их влияния, можно получать люминофоры с различным цветом свечения, включая „белые

Актуальность исследования $\mathrm{ZnS}$ в настоящее время связана с особенностями проявления свойств веществом в наноразмерном состоянии [3,7-11], а также с возможностью получения сложных полупроводниковых структур типа „ядро/оболочка“ и „ядро/оболочка/оболочка“, отличающихся своими оптическими характеристиками $[10,12,13]$.

Для описания люминесценции полупроводниковых структур применяются модели Шёна-Клазенса, ЛамбеКлика, Вильямса-Пренера $[14,15]$. Возбуждение люминесценции связано с межзонным переходом электронов из валентной зоны $\mathrm{ZnS}$ в зону проводимости. Для объемных кристаллов $\mathrm{ZnS}$ при длинах волн 380-390 nm зарегистрирована люминесценция „чистого“ сульфида цинка [1]. При длинах волн > $400 \mathrm{~nm}$ наблюдается „самоактивированная“ люминесценция $\mathrm{ZnS}$. Она связана с рекомбинационными процессами, происходящими на уровнях дефектов кристаллической структуры ZnS. Полосы люминесценции, расположенные при длинах волн $<480 \mathrm{~nm}$, связывают с уровнями энергии, образованными однократно отрицательно заряженными вакансиями ионов цинка $\left(V_{\mathrm{Zn}}^{\prime}\right)[1,16]$. „Зеленую“ люминесценцию $\mathrm{ZnS}$ объясняют протеканием рекомбинационных процессов на уровнях, образованных двухзарядными вакансиями ионов цинка $\left(V_{\mathrm{Zn}}^{\prime \prime}\right)[1,16]$ и вакансиями серы $\left(V_{\mathrm{S}}\right)[16,17]$. Сложность полос люминесценции объясняется политипностью кристаллов $\mathrm{ZnS}$, влиянием кислорода, наличием различных примесей $[3,4,18]$.

Большая ширина запрещенной зоны $(3.68 \mathrm{eV}$ при $300 \mathrm{~K}$ ) позволяет существенно изменять энергетическую диаграмму $\mathrm{ZnS}$, введением в его состав легирующих катионов ( $\mathrm{Cu}, \mathrm{Mn}, \mathrm{Pb}$ и др.) [1,6,16,17,19-21]. Они замещают ионы цинка в его подрешетке и занимают пустоты в кристаллической структуре ZnS. На энергетической диаграмме возникают соответствующие им уровни энергии, определяющие люминесценцию $\mathrm{ZnS}$. Кроме того, наблюдается внутрицентровая люминесценция, обусловленная переходами между собственными уровнями энергии легирующих катионов.

Легирование $\mathrm{ZnS}$ ионами меди позволяет получать люминофоры с полосами различной интенсивности в голубой, зеленой и желтой областях спектра. Авторами [6] отмечено, что соотношение интенсивностей полос и время деградации возбужденных состояний зависят от условий приготовления люминесцирующих структур и вида 
подложки на которую нанесен люминесцирующий слой $\mathrm{ZnS}-\mathrm{Cu}$, а также способа синтеза люминофоров [6]. В работе $[6,16]$ отмечено, что люминофор $\mathrm{ZnS} / \mathrm{Cu}$ ярко люминесцирует в зеленой области спектра $(525 \mathrm{~nm})$ с высоким квантовым выходом люминесценции. Он используется для визуализации рентгеновского излучения.

Сульфид серебра $\mathrm{Ag}_{2} \mathrm{~S}$ относится к узкозонным полупроводникам с шириной запрещенной зоны $0.9-1.1 \mathrm{eV}$. Как полупроводниковое соединение он вызывает большой интерес благодаря химической стабильности и простоте синтеза. Пленки и порошки $\mathrm{Ag}_{2} \mathrm{~S}$ применяются в оптоэлектронной технике и энергетике, в фотогальванических элементах и фотохимических ячейках [22,23], в ИК-детекторах [23,24], преобразователях солнечной энергии $[23,25,26]$. Применение объемных кристаллов $\mathrm{Ag}_{2} \mathrm{~S}$ осложнено фазовым превращением при достаточно низкой температуре. Характеристики такого превращения в нанокристаллическом сульфиде серебра неизвестны [23]. В работе [27] показано, что при увеличении концентрации ионов $\mathrm{Ag}^{+}$на поверхности кристаллов $\mathrm{CdS}$ образуется $\mathrm{Ag}_{2} \mathrm{~S}$. Он тушит видимую люминесценцию $\mathrm{CdS}$ в результате блокирования излучающих центров и ограничения проникновения возбуждающего излучения внутрь кристаллов.

Большой интерес привлекает легирование полупроводников ионам лантаноидов $[7,11,28-40]$. Этот интерес объясняется их оптическими свойствами, возможностью получения изолированных центров свечения в полупроводниковой матрице с интенсивной узкополосной люминесценцией. Возбуждение люминесценции и люминесценция КТ, легированных лантаноидами, связаны с межзонным переходом электронов в полупроводниковой матрице и примесными уровнями в запрещенной зоне полупроводника, а также с собственными электронными переходами в ионах $\mathrm{Ln}^{3+}$. Кроме того, зарегистрирован перенос энергии с полупроводниковой матрицы, на уровни $\mathrm{Ln}^{3+}$, увеличивающий интенсивность их люминесценции $[30,33,34]$.

Для получения наноразмерных полупроводниковых структур применяются золь-гель технологии синтеза $[4,8,41-46]$. В качестве сульфидизатора используются $\mathrm{H}_{2} \mathrm{~S}, \mathrm{Na}_{2} \mathrm{~S}$, сераорганические соединения $[4,37,38,41,43,44,46]$. КТ выделяют из растворов в виде порошка, наносят на различные подложки [34,47]. Размер КТ, как правило, не превышает $10 \mathrm{~nm}[30,38,43,46,48]$. В процессе синтеза ионы $\mathrm{Ln}^{3+}$ оказываются включенными в кристаллическую структуру полупроводника в объеме или на поверхности частиц $[33,37-39,49]$. Синтез проводится преимущественно в водной среде. Остаточные молекулы воды и гидроксосоединения являются эффективными тушителями люминесценции лантаноидов. Применение неводной реакционной среды минимизирует влияние этого фактора. Синтез в среде ММА позволяет получать КТ сульфидов металлов и их структур непосредственно в полимеризующейся безводной среде, а также дополнительно стабилизировать их, изолировав в пустотах полимерной матрицы [37,50-54]. Прозрачность акрилатного „стекла“ при длинах волн > $500 \mathrm{~nm}$ достигает 92\% (5 mm). Размер неагрегированных КТ составляет 3-7 nm [37,46]. Размер агрегатов достигает десятков нанометров [46,54].

Исследования, направленные на изучение люминесценции полупроводниковых структур, одновременно легированных ионами различных металлов ограничены, несмотря на появляющуюся возможность реализации дополнительных путей управления энергетическими потоками возбуждения люминесценции и люминесценции.

Цель данной работы состояла в изучении одновременного влияния ионов меди, серебра и европия на люминесценцию полупроводниковых структур на основе сульфида цинка, заключенных в полиакрилатную матрицу.

\section{2. Синтез и методы исследования}

Квантовые точки ZnS, (Zn,Cu)S, (Zn,Ag)S, $(\mathrm{Zn}, \mathrm{Cu}, \mathrm{Ag}) \mathrm{S}$ и $(\mathrm{Zn}, \mathrm{Cu}, \mathrm{Ag}) \mathrm{S}: \mathrm{Eu}^{3+}$ синтезированы взаимодействием трифторацетата цинка с тиоацетамидом в среде метилметакрилата (ММА), аналогично [38,52]. Одновременно с трифторацетатом цинка и тиоацетамидом в растворы вводили трифторацетаты меди, серебра и европия в различных концентрационных соотношениях. Выбор трифторацетатов металлов обусловлен их хорошей растворимостью в метилметакрилате [55]. На первой стадии синтеза в растворе образовывались тиоацетамидные комплексы металлов. При нагревании комплексы разрушались с образованием сульфидов металлов [56]. Разрушение комплексов и образование сульфидов продолжалось в процессе термической полимеризации ММА в блоке. Концентрация трифторацетатов металлов в исходных растворах была равна: цинка $-1 \cdot 10^{-2} \mathrm{~mol} / \mathrm{L}$; меди и серебра по $1 \cdot 10^{-3} \mathrm{~mol} / \mathrm{L}$; европия $-1 \cdot 10^{-4} \mathrm{~mol} / \mathrm{L}, 5 \cdot 10^{-4} \mathrm{~mol} / \mathrm{L}$ и $1 \cdot 10^{-3} \mathrm{~mol} / \mathrm{L}$. Таким образом, мольные соотношения $\mathrm{Zn}: \mathrm{Cu}: \mathrm{Ag}: \mathrm{Eu}$ в растворах были равны: $1: 0: 0: 0,1: 0.1: 0: 0$, $1: 0: 0.1: 0,1: 0.1: 0.1: 0,1: 0.1: 0.1: 0.01,1: 0.1: 0.1: 0.05$, $1: 0.1: 0.1: 0.1$. При выборе концентрации и мольных соотношений солей металлов исходили из данных, приведенных в работах $[37,46,56]$. Концентрация тиоацетамида во всех растворах была равна концентрации трифторацетата цинка. Для инициирования полимеризации ММА в растворы вводили перекись бензоила в количестве $0.10 \%$ от его массы. Объем полимеризуемых растворов составлял $10 \mathrm{ml}$. Растворы полимеризовали до вязкого состояния при температуре $60-70^{\circ} \mathrm{C}$. Вязкими растворами заполняли стеклянные кюветы и продолжали нагревать до перехода композиции в стеклообразное состояние. Общее время полимеризации составляло $24 \mathrm{~h}$. В результате получены прозрачные акрилатные „стекла“ состава ПММА/ZnS, ПММА/(Zn, Cu $) \mathrm{S}, \quad$ ПMМА/(Zn, Ag)S, ПММА/(Zn, $\mathrm{Cu}, \mathrm{Ag}) \mathrm{S}$ и ПММА/(Zn, $\mathrm{Cu}, \mathrm{Ag}) \mathrm{S}: \mathrm{Eu}^{3+}$.

Оптические спектры поглощения, возбуждения люминесценции и люминесценции композиций зарегистриро- 
ваны на спектрофлуориметре CM 2203 „Solar“. Спектры поглощения ПММА записаны относительно воздуха. Спектры поглощения композиций - относительно пластин ПММА сопоставимой толщины. При регистрации спектров люминесценции возбуждающий свет источника излучения (ксеноновая дуговая лампа высокого давления ДКсШ 150-1М) падал на образец перпендикулярно его поверхности. Стационарную фотолюминесценцию регистрировали под углом $45^{\circ}$. Спектры возбуждения люминесценции регистрировали в области максимума полос люминесценции композиций.

\section{3. Результаты и обсуждение}

Оптические свойства ПММА достаточно хорошо изучены и представлены в научной литературе [57]. „Стекла“ ПММА интенсивно поглощают излучение УФ области электромагнитного спектра. Край полосы поглощения для образцов ПММА толщиной $5 \mathrm{~mm}$ находится в области длин волн $\sim 300 \mathrm{~nm}$. В видимой области спектра пропускание ПММА достигает 92\% (5 mm).

Длинноволновая полоса люминесценции ПММА расположена при длинах волн $<480 \mathrm{~nm}$. Она связана с продуктами разложения перекиси бензоила, которую вводили в реакционную смесь для инициирования полимеризации ММА. Интенсивность полосы невысока.

В оптических спектрах поглощения композиций ПMMA/ZnS зарегистрирована широкая полоса с максимумом в области $300-310 \mathrm{~nm}$. Она связана с наноразмерными частицами $\mathrm{ZnS}$ [58]. В спектрах композиций ПMMA/( $\mathrm{Zn}, \mathrm{Cu}) \mathrm{S}$ при равных концентрациях ионов цинка и меди полоса смещена в длинноволновую часть спектра до $324 \mathrm{~nm}$. Ее интенсивность увеличивается с увеличением концентрации ионов меди [52]. Неоднородное уширение и структура полосы при увеличении концентрации ионов меди объясняются образованием различных поглощающих центров, включая ионные ассоциаты вида $\mathrm{Cu}_{\mathrm{I}}^{2+}-\mathrm{Cu}_{\mathrm{V}}^{2+}$, где $\mathrm{Cu}_{\mathrm{I}}^{2+}-$ ион меди в междоузлии кристаллической структуры $\mathrm{ZnS}, \mathrm{Cu}_{\mathrm{V}}^{2+}-$ ион меди в узле кристаллической структуры $\mathrm{ZnS}$ на позиции иона цинка [20]. Аналогичные изменения наблюдаются в спектре композиций ПММА/(Zn, Ag)S. Длинноволновое смещение спектральной полосы при увеличении в составе композиции концентрации ионов $\mathrm{Ag}^{+}$также связано с образованием сульфида серебра на поверхности частиц $\mathrm{ZnS}$. На это указывает появление коричневой окраски композиций при увеличении концентрации ионов серебра в исходном растворе $>5 \cdot 10^{-3} \mathrm{~mol} / \mathrm{L}$, как это замечено в работе [27].

Средний размер частиц $\mathrm{ZnS}$, рассчитанный из спектральных данных по методике [3], составляет 5-7 nm. После легирования он увеличивается. На это указывает длинноволновое смещение точки пересечения касательных, проведенных к ниспадающим ветвям полос поглощения частиц в спектрах композиций [52]. Результат соответствует полученным ранее данным [44,46,54].

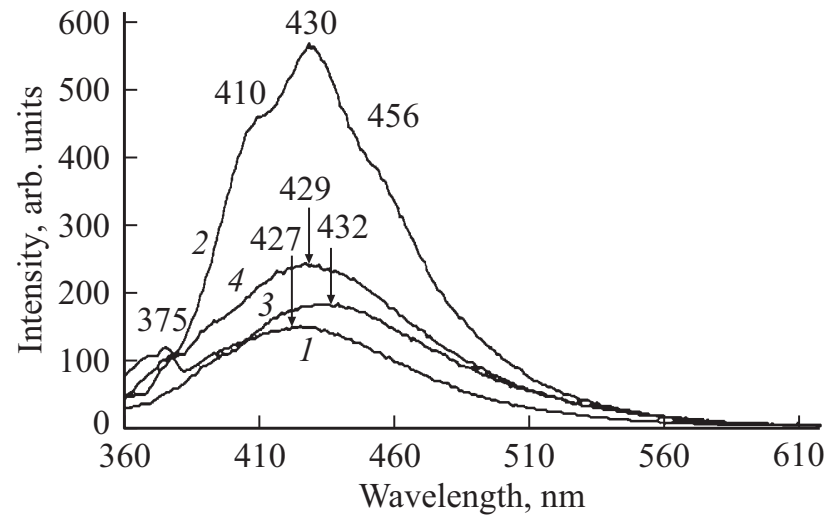

Рис. 1. Спектры люминесценции композиций $\left(\lambda_{\mathrm{exc}}=360 \mathrm{~nm}\right)$, положение максимумов, nm: 1 - ПММА/ZnS $(375,427) ; 2-$ ПMМА/(Zn, Cu)S (410, 430, 456); $3-\Pi \mathrm{MMA} /(\mathrm{Zn}, \mathrm{Ag}) \mathrm{S}$ (432); 4 - ПММА/ $(\mathrm{Zn}, \mathrm{Cu}, \mathrm{Ag}) \mathrm{S}(429) ; C_{\mathrm{Zn}}=1 \cdot 10^{-2} \mathrm{~mol} / \mathrm{L}$ реакционной смеси, $C_{\mathrm{Cu}}=C_{\mathrm{Ag}}=1 \cdot 10^{-3} \mathrm{~mol} / \mathrm{L}$ реакционной смеси.

Увеличение размера легированных частиц связано с внедрением в кристаллическую решетку $\mathrm{ZnS}$ ионов, имеющих больший радиус, а также, как следует из данных просвечивающей электронной микроскопии, с образованием на поверхности частиц слоя комплексных соединений [46,54].

Совокупность результатов, полученных из оптических спектров поглощения и электронной микроскопии, а также данных, приведенных авторами работы [59] для аналогичных систем, с учетом значительно меньшей растворимости сульфидов меди и серебра относительно растворимости сульфида цинка и, в тоже время, на порядок меньшей концентрации их предшественников в реакционных смесях, подтверждают внедрение ионов меди и серебра в объем кристаллов $\mathrm{ZnS}$ и в структуру их поверхности. Ионы меди и серебра на поверхности кристаллов $\mathrm{ZnS}$, взаимодействуя с компонентами среды, в качестве которых выступают трифторацетат-ионы и карбонилсодержащие мономерные звенья, образуют комплексные соединения, насыщая этим свои координационные возможности. Появление коричневой окраски $\mathrm{Ag}_{2} \mathrm{~S}$ при концентрации ионов серебра $>5 \cdot 10^{-3} \mathrm{~mol} / \mathrm{l}$ реакционной смеси, указывает на увеличение доли легирующих ионов в приповерхностном слое кристаллов $\mathrm{ZnS}$ и на их поверхности, указывая этим на их неравномерное распределение от ядра к поверхности частиц, подтверждает возможность получения структур „ядро/оболочка“ с увеличением концентрации легирующих ионов в реакционных смесях, превышающей заявленные в данной работе.

В спектре люминесценции композиции ПММA/ZnS при возбуждении излучением с длиной волны $360 \mathrm{~nm}$ зарегистрирована широкая сложная полоса с основным максимумом в области $427 \mathrm{~nm}$, а также слабая полоса с максимумом в области $375 \mathrm{~nm}$ (рис. 1, спектр 1). Ее связывают с вакансиями в подрешетке цинка $\left(V_{\mathrm{Zn}}^{\prime}\right)[1,16]$. Неоднородное уширение и структура спектральных по- 
лос связаны с несовершенством кристаллической структуры $\mathrm{ZnS}$, ее политипностью в ядрах коллоидных частиц на стадии их формирования, с влиянием аморфной матрицы.

B спектрах люминесценции композиций ПMМА/(Zn, Cu $) \mathrm{S}, \quad$ ПMМА/ $(\mathrm{Zn}, \mathrm{Ag}) \mathrm{S}$ и ПMМA/(Zn, $\mathrm{Cu}, \mathrm{Ag}) \mathrm{S}, \quad$ коротковолновая полоса отсутствует (рис. 1, спектры 2-4). Это связано с увеличением в приповерхностном слое и на поверхности частиц сульфидов серебра и меди, или их смеси, ограничивающих проникновение возбуждающего излучения внутрь частиц. Отмечена тенденция к смещению длинноволновой полосы люминесценции в область длинных волн $(427 \rightarrow 429 \rightarrow 430 \rightarrow 432 \mathrm{~nm})$, в большей степени проявившемуся для композиций, содержащих в качестве легирующего компонента только ионы серебра, что можно связать с изменением структуры поверхности частиц и с ролью образующегося на их поверхности наименее растворимого из примененных сульфидов $\mathrm{Ag}_{2} \mathrm{~S}$.

B спектрах люминесценции композиции ПММА/(Zn, Cu $) \mathrm{S}$ зарегистрировано увеличение интенсивности и появление структуры полосы (рис. 1, спектр 2). Максимумы ее отдельных компонент расположены в области длин волн 410, 430 и $456 \mathrm{~nm}$. Увеличенную интенсивность полосы объясняем внедрением оптимального количества ионов меди в структуру поверхности $\mathrm{ZnS}$. Структурирование полосы связываем с образованием различных поглощающих центров, в том числе ионных пар $\mathrm{Cu}-\mathrm{Cu}$ на поверхности частиц. Более низкую интенсивность полос люминесценции композиций ПММА/ $(\mathrm{Zn}, \mathrm{Ag}) \mathrm{S}$ и ПММА/ $(\mathrm{Zn}, \mathrm{Cu}, \mathrm{Ag}) \mathrm{S}$ (рис. 1, спектры 3 и 4), относительно интенсивности полосы люминесценции композиции ПММА/ $(\mathrm{Zn}, \mathrm{Cu}) \mathrm{S}$ (рис. 1, спектр 2), связываем с образованием на поверхности частиц легированного $\mathrm{ZnS}$ сульфида серебра, ширина запрещенной зоны которого очень мала, блокирующего часть люминесцирующих центров и ограничивающего проникновение возбуждающего излучения внутрь частиц. В тоже время, некоторое увеличение интенсивности этих полос (рис. 1, спектры 3 и 4) относительно интенсивности полосы люминесценции композиции ПММА/ZnS (рис. 1, спектр 1) объясняется образованием дополнительных дефектов на поверхности кристаллов $\mathrm{ZnS}$ при внедрении в ее структуру ионов меди и серебра.

При возбуждении люминесценции композиций излучением с длиной волны $395 \mathrm{~nm}$ интенсивность полос люминесценции уменьшается (рис. 2). Структура полосы люминесценции композиции ПММА/( $\mathrm{Zn}, \mathrm{Cu}) \mathrm{S}$ становится более выраженной (рис. 2, спектр 2). Структурирование данной полосы можно объяснить оптимизацией переноса энергии между уровнями дефектов в запрещенной зоне легированного $\mathrm{ZnS}$. Небольшой пик в области длин волн $410 \mathrm{~nm}$ в спектрах композиций, включая спектр ПММA/ZnS (рис. 2, спектры 1,3,4), вероятно, связан с люминесценцией ассоциированных дефектов, например, $V_{\mathrm{Zn}}-V_{\mathrm{Zn}}^{\prime}$, близких по энергии к

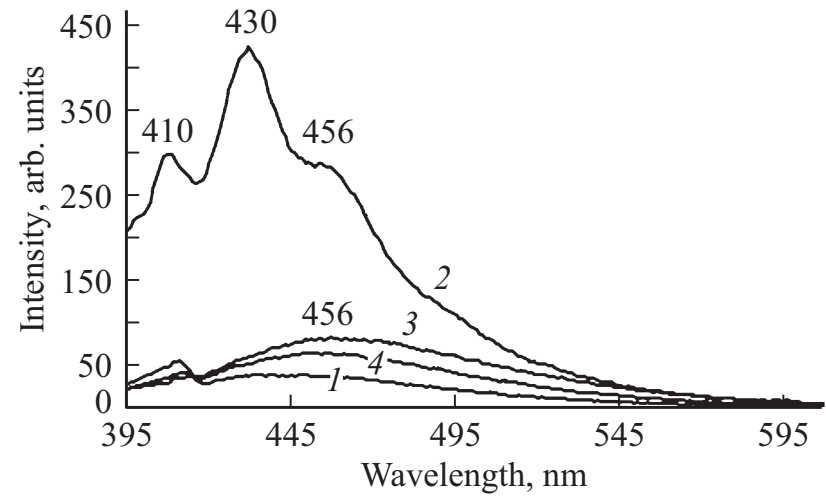

Рис. 2. Спектры люминесценции композиций $\left(\lambda_{\operatorname{exc}}=395 \mathrm{~nm}\right)$, положение максимумов, $\mathrm{nm}: 1-$ ПММА/ZnS (456); 2 ПMMA/(Zn, Cu)S (410, 430, 456); 3 - ПMMA/(Zn, Ag)S (456); 4 - ПММА $/(\mathrm{Zn}, \mathrm{Cu}, \mathrm{Ag}) \mathrm{S}(456) ; C_{\mathrm{Zn}}=1 \cdot 10^{-2} \mathrm{~mol} / \mathrm{L}$ реакционной смеси, $C_{\mathrm{Cu}}=C_{\mathrm{Ag}}=1 \cdot 10^{-3} \mathrm{~mol} / \mathrm{L}$ реакционной смеси.

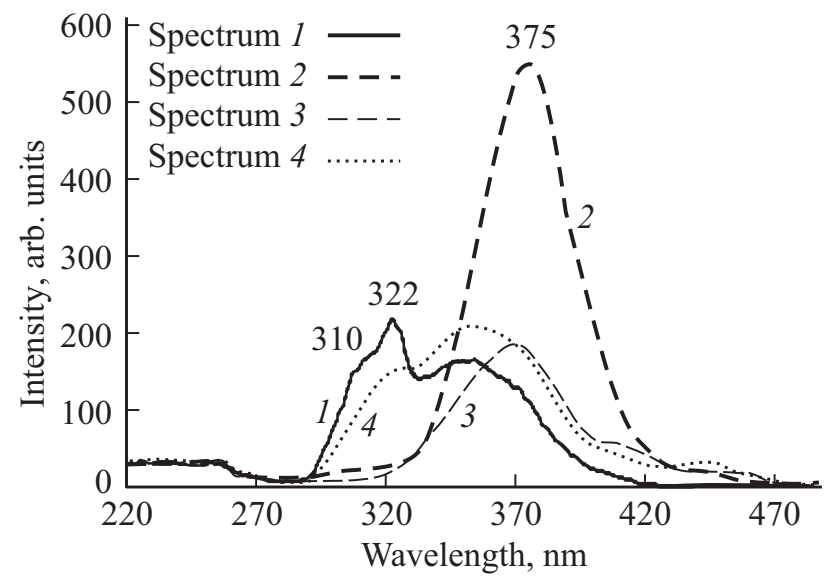

Рис. 3. Спектры возбуждения люминесценции композиций $\left(\lambda_{\mathrm{em}}, \mathrm{nm} ; \lambda_{\max }, \mathrm{nm}\right): 1-\Pi \mathrm{MMA} / \mathrm{ZnS}(424 ; 310,322,346) ; 2-$ ПММА/(Zn, Cu)S (450; 375); 3 - ПММА/(Zn, Ag)S (450; 369); $4-\Pi$ МMA $/(\mathrm{Zn}, \mathrm{Cu}, \mathrm{Ag}) \mathrm{S}(450 ; 322,357) ; C_{\mathrm{Zn}}=1 \cdot 10^{-2} \mathrm{~mol} / \mathrm{L}$ реакционной смеси, $C_{\mathrm{Cu}}=C_{\mathrm{Ag}}=1 \cdot 10^{-3} \mathrm{~mol} / \mathrm{L}$ реакционной смеси.

энергии межионных ассоциатов, включая ассоциаты вида $\mathrm{Cu}-\mathrm{Cu}$.

В спектрах возбуждения люминесценции композиций для излучения с длиной волны 424 и $450 \mathrm{~nm}$ зарегистрированы полосы в диапазоне длин волн 280-420 nm (рис. 3). Полосы композиций, содержащих легированный $\mathrm{ZnS}$, смещены в длинноволновую часть спектра. В спектрах композиций ПММA/ZnS и ПММА/ $(\mathrm{Zn}, \mathrm{Cu}, \mathrm{Ag}) \mathrm{S}$ они структурированы (рис. 3 , спектры 1 и 4). Это связано с неоднородностью люминесцирующих центров, в частности, расположением легирующих ионов в объеме и на поверхности частиц, а также с неоднородностью поверхности, возникающей при взаимном влиянии легирующих ионов. Исчезновение коротковолновой компоненты полос в спектрах композиций ПММА/(Zn, Ag)S и ПMMA/ $(\mathrm{Zn}, \mathrm{Cu}) \mathrm{S}$ объясняется образованием на поверх- 
ности частиц сульфидов серебра и меди, блокирующих проникновение излучения в их объем. В спектре композиции ПММА/(Zn, Cu, Ag)S полоса занимает промежуточное положение (рис. 3, спектр 4). Это подтверждает предположение о взаимном влиянии легирующих ионов на структуру поверхности частиц.

Перекрывание коротковолновой полосы в спектрах возбуждения люминесценции композиций ПММA/ZnS и ПМMA/( $\mathrm{Zn}, \mathrm{Cu}, \mathrm{Ag}) \mathrm{S}$ с полосой оптического поглощения $\mathrm{ZnS}$ связывает процесс возбуждения люминесценции с межзонным переходом электронов в сульфиде цинка. Кроме того, перекрывание полос возбуждения люминесценции с длинноволновыми полосами оптического поглощения композиций указывает на возбуждение люминесценции при переходах электронов из валентной зоны на уровни дефектов структуры $\mathrm{ZnS}$. Далее наблюдается релаксация при переходах между уровнями дефектов структуры и рекомбинация с выделением кванта оптического излучения.

В спектрах люминесценции композиций ПММА/(Zn, $\mathrm{Cu}, \mathrm{Ag}) \mathrm{S}: \mathrm{Eu}^{3+}\left(\lambda_{\mathrm{exc}}=360 \mathrm{~nm}\right)$ с различной концентрацией ионов $\mathrm{Eu}^{3+}$ максимумы широких спектральных полос находятся в области $430 \mathrm{~nm}$ (рис. 4). Их интенсивность уменьшается при увеличении концентрации ионов $\mathrm{Eu}^{3+}$. Это обстоятельство подтверждает протекание процессов поглощения и эмиссии энергии на поверхности частиц, и закрепление на ней ионов $\mathrm{Eu}^{3+}$. Кроме того, в спектрах зарегистрированы полосы люминесценции, связанные с ${ }^{5} D_{0} \rightarrow{ }^{7} F_{1,2,4}$ переходами электронов между собственными уровнями ионов $\mathrm{Eu}^{3+}$. Полосы также являются неоднородно уширенными. С увеличением концентрации ионов $\mathrm{Eu}^{3+}$ интенсивность данных полос увеличивается, возрастает

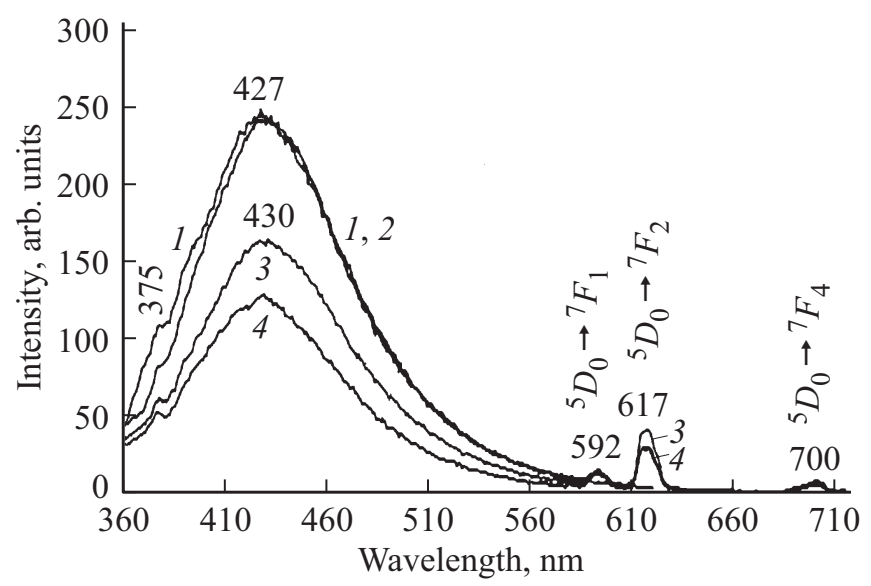

Рис. 4. Спектры люминесценции композиций $\left(\lambda_{\mathrm{exc}}=360 \mathrm{~nm}\right)$, положение максимумов, nm; концентрация ионов $\mathrm{Eu}^{3+}, \mathrm{mol} / \mathrm{L}$ полимеризуемой смеси: 1 - ПММА $/(\mathrm{Zn}, \mathrm{Cu}, \mathrm{Ag}) \mathrm{S} \quad(375$, 427); 2 П ПММА/(Zn, Cu, Ag)S: $\mathrm{Eu}^{3+} \quad\left(427 ; 1 \cdot 10^{-4}\right)$; $3-\Pi$ - ПМА $/(\mathrm{Zn}, \mathrm{Cu}, \mathrm{Ag}) \mathrm{S}: \mathrm{Eu}^{3+} \quad(430, \quad 595, \quad 619, \quad 700$; $\left.5 \cdot 10^{-4}\right) ; 4-$ ПMMA/(Zn, Cu, Ag)S: $\mathrm{Eu}^{3+} \quad(428,592,617$, $\left.700 ; \quad 1 \cdot 10^{-3}\right) ; \quad C_{\mathrm{Zn}}=1 \cdot 10^{-2} \mathrm{~mol} / \mathrm{L}$ реакционной смеси, $C_{\mathrm{Cu}}=C_{\mathrm{Ag}}=1 \cdot 10^{-3} \mathrm{~mol} / \mathrm{L}$ реакционной смеси.

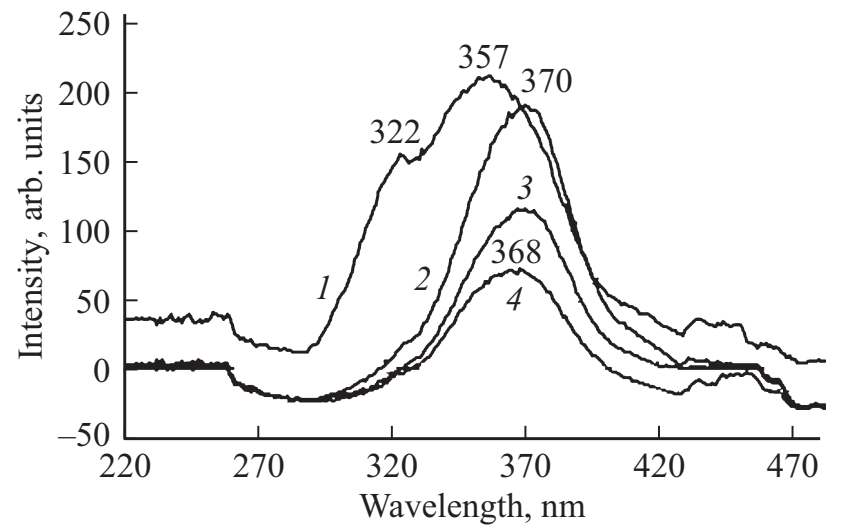

Рис. 5. Спектры возбуждения люминесценции композиций $\left(\lambda_{\mathrm{em}}=450 \mathrm{~nm}\right)$, положение максимумов, $\mathrm{nm}$; концентрация ионов $\mathrm{Eu}^{3+}, \mathrm{mol} / \mathrm{L}$ полимеризуемой смеси: 1 - ПМ$\mathrm{MA} /(\mathrm{Zn}, \mathrm{Cu}, \mathrm{Ag}) \mathrm{S}(322,357) ; 2-\Pi \mathrm{MMA} /(\mathrm{Zn}, \mathrm{Cu}, \mathrm{Ag}) \mathrm{S}: \mathrm{Eu}^{3+}$ $\left(370 ; \quad 1 \cdot 10^{-4}\right) ; \quad 3-\Pi M M A /(Z n, C u, A g) S: E u^{3+}$ $\left(370 ; \quad 5 \cdot 10^{-4}\right) ; \quad 4-\Pi M M A /(Z n, C u, A g) S: \mathrm{Eu}^{3+}$ $\left(368 ; 1 \cdot 10^{-3}\right) ; \quad C_{\mathrm{Zn}}=1 \cdot 10^{-2} \mathrm{~mol} / \mathrm{L}$ реакционной смеси, $C_{\mathrm{Cu}}=C_{\mathrm{Ag}}=1 \cdot 10^{-3} \mathrm{~mol} / \mathrm{L}$ реакционной смеси.

вероятность распределения ионов $\mathrm{Eu}^{3+}$ внутри матрицы в несвязанном с частицами полупроводника состоянии.

В спектрах возбуждения люминесценции, зарегистрированных для люминесценции с длиной волны $450 \mathrm{~nm}$, наблюдаются широкие полосы в интервале длин волн 280-430 nm (рис. 5). В спектрах европийсодержащих композиций полосы не структурированы (рис. 5, спектры 2-4). Наиболее интенсивной является длинноволновая компонента полос с максимумом в области $370 \mathrm{~nm}$. Перекрывание полосы в спектре возбуждения люминесценции с длинноволновой полосой в оптическом спектре поглощения композиций ПММА/( $\mathrm{Zn}, \mathrm{Cu}, \mathrm{Ag}) \mathrm{S}: \mathrm{Eu}^{3+}$ связывает возникновение люминесценции с поглощением в результате перехода электронов из валентной зоны полупроводника на примесные уровни дефектов, расположенных на поверхности частиц легированного $\mathrm{ZnS}$. Далее происходит релаксация и выделение части энергии в виде люминесценции при рекомбинации электрон-дырочных пар на уровнях дефектов. Можно отметить малую вероятность участия в процессе возбуждения люминесценции уровней внутрикристаллических дефектов и непосредственно межзонного перехода в $\mathrm{ZnS}$. На это указывает слабая интенсивность полосы возбуждения люминесценции в области длин волн $<320$ n்m, связанной с межзонным переходом в $\mathrm{ZnS}$

Спектры люминесценции европийсодержащих композиций при возбуждении излучением с длиной волны $395 \mathrm{~nm}$ приведены на рис. 6. Данной длине волны соответствует полоса собственного абсорбционного ${ }^{7} F_{0} \rightarrow{ }^{5} L_{6}$ электронного перехода ионов $\mathrm{Eu}^{3+}$. Она перекрывается с ниспадающей ветвью полосы поглощения, легированного $\mathrm{ZnS}$. Действуя на композицию излучением $395 \mathrm{~nm}$, возбуждаем как рекомбинацион- 


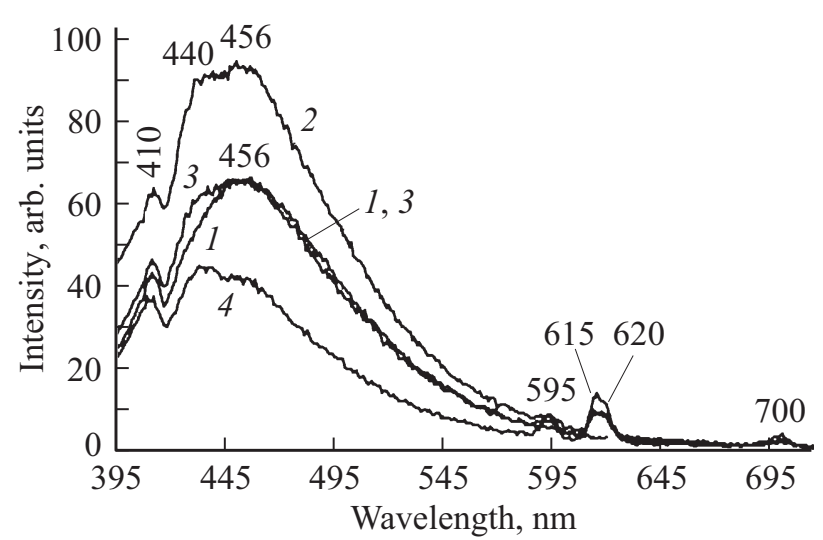

Pис. 6. Спектры люминесценции композиций $\left(\lambda_{\mathrm{exc}}=395 \mathrm{~nm}\right)$, положение максимумов, $\mathrm{nm}$; концентрация ионов $\mathrm{Eu}^{3+}, \mathrm{mol} / \mathrm{L}$ полимеризуемой смеси: 1 - ПММА/( $\mathrm{Zn}, \mathrm{Cu}, \mathrm{Ag}) \mathrm{S}(410,456)$; 2 - ПММА/(Zn, Cu, Ag)S: $\mathrm{Eu}^{3+}\left(410,440,456 ; 1 \cdot 10^{-4}\right)$; 3 - ПММА/(Zn, Cu, Ag)S: $\mathrm{Eu}^{3+}(410,440,456,595,615,620$, 700; $\left.5 \cdot 10^{-4}\right) ; 4-\Pi M M A /(\mathrm{Zn}, \mathrm{Cu}, \mathrm{Ag}) \mathrm{S}: \mathrm{Eu}^{3+}(410,440,456$, $\left.595,615,620,700 ; 1 \cdot 10^{-3}\right) ; C_{\mathrm{Zn}}=1 \cdot 10^{-2} \mathrm{~mol} / \mathrm{L}$ реакционной смеси, $C_{\mathrm{Cu}}=C_{\mathrm{Ag}}=1 \cdot 10^{-3} \mathrm{~mol} / \mathrm{L}$ реакционной смеси.

ную люминесценцию полупроводниковых структур, так и внутрицентровые переходы электронов по уровням ионов $\mathrm{Eu}^{3+}$.

Спектральная полоса рекомбинационной люминесценции композиций ПММА/ $(\mathrm{Zn}, \mathrm{Cu}, \mathrm{Ag}) \mathrm{S}: \mathrm{Eu}^{3+}$ $(395-550 \mathrm{~nm})$ уширена и смещена в коротковолновую часть спектра (рис. 2 и 6). Аналогичные изменения зарегистрированы для наиболее интенсивной полосы люминесценции ионов $\mathrm{Eu}^{3+}\left({ }^{5} D_{0} \rightarrow{ }^{7} F_{2}\right.$ электронный переход, 615-620 nm). В их структуре наблюдаются компоненты с максимумами (410, 440, $456 \mathrm{~nm})$ и $(615$, $620 \mathrm{~nm}$ ), соответственно (рис. 6). Структурирование широкой полосы люминесценции связано с влиянием ионов $\mathrm{Eu}^{3+}$, входящих в структуру поверхности частиц $(\mathrm{Zn}, \mathrm{Cu}, \mathrm{Ag}) \mathrm{S}: \mathrm{Eu}^{3+}$. Их внедрение в структуру поверхности легированных кристаллов $\mathrm{ZnS}$ приводит к изменению характера межионных взаимодействий на поверхности частиц и уменьшению блокировочного действия $\mathrm{Ag}_{2} \mathrm{~S}$ в силу фактора разведения. Это, вероятно, приводит к формированию более однородной структуры поверхности с ограниченным набором люминесцирующих центров. Это подтверждается увеличением интенсивности полосы рекомбинационной люминесценции $(456 \mathrm{~nm})$ при малых концентрациях ионов $\mathrm{Eu}^{3+}$ $\left(<5 \cdot 10^{-4}\right)$ (рис. 6, спектр 2), относительно полосы в спектре люминесценции композиции, не содержащей ионов $\mathrm{Eu}^{3+}$ (рис. 6, спектр 1). Уменьшение интенсивности полос (рис. 6, спектры 3 и 4, $456 \mathrm{~nm}$ ) при увеличении концентрации ионов $\mathrm{Eu}^{3+}$ объясняется усилением роли комплексов европия на поверхности частиц. Это подтверждается появлением структуры собственной полосы люминесценции ионов $\mathrm{Eu}^{3+}$ при длине волны $615 \mathrm{~nm}$. Дуплетная структура полосы люминесценции ионов $\mathrm{Eu}^{3+}(615$ и $620 \mathrm{~nm})$ может проявиться в результате штарковского расщепления уровней энергии при внедрении ионов $\mathrm{Eu}^{3+}$ в структуру кристаллов полупроводника, а также в результате образования люминесцирующих европиевых центров, связанных с частицами легированного полупроводника, комплексами на поверхности частиц и распределением в объеме полимерной матрицы в несвязанном с частицами полупроводника виде.

В спектрах возбуждения люминесценции композиций ПММА/ $(\mathrm{Zn}, \mathrm{Cu}, \mathrm{Ag}) \mathrm{S}: \mathrm{Eu}^{3+}$ (рис. 7), зарегистрированных для люминесценции ${ }^{5} D_{0} \rightarrow{ }^{7} F_{2}$ электронного перехода ионов $\mathrm{Eu}^{3+}(615 \mathrm{~nm})$, кроме широкой полосы возбуждения люминесценции легированного $\mathrm{ZnS}$ $\left(\lambda_{\max } \sim 353 \mathrm{~nm}\right)$, наблюдаются полосы, связанные с собственными ${ }^{7} F_{0} \rightarrow{ }^{5} L_{6}(395 \mathrm{~nm})$ и ${ }^{7} F_{0} \rightarrow{ }^{5} D_{2} \quad(466 \mathrm{~nm})$ электронными переходами ионов $\mathrm{Eu}^{3+}$. Слабая полоса возбуждения люминесценции в спектре композиции ПММА/(Zn, $\mathrm{Cu}, \mathrm{Ag}) \mathrm{S}$ в области $300 \mathrm{~nm}$ (рис. 7, спектр 1) соответствует практически полному отсутствию у них люминесценции при длинах волн > $590 \mathrm{~nm}$ (рис. 6, спектр 1). Эта полоса связана с переносом энергии межзонного перехода в $\mathrm{ZnS}$ на уровни внутрикристаллических дефектов в его структуре. Исчезновение этой полосы в спектрах европийсодержащих композиций и наличие длинноволновой полосы возбуждения с максимумом в области $350 \mathrm{~nm}$ подтверждает связь люминесценции $(615 \mathrm{~nm})$ с процессами, протекающими с участием ионов $\mathrm{Eu}^{3+}$ на поверхности частиц. Увеличение интенсивности полосы $(350 \mathrm{~nm})$ при увеличении концентрации ионов $\mathrm{Eu}^{3+}$ объясняется возникновением

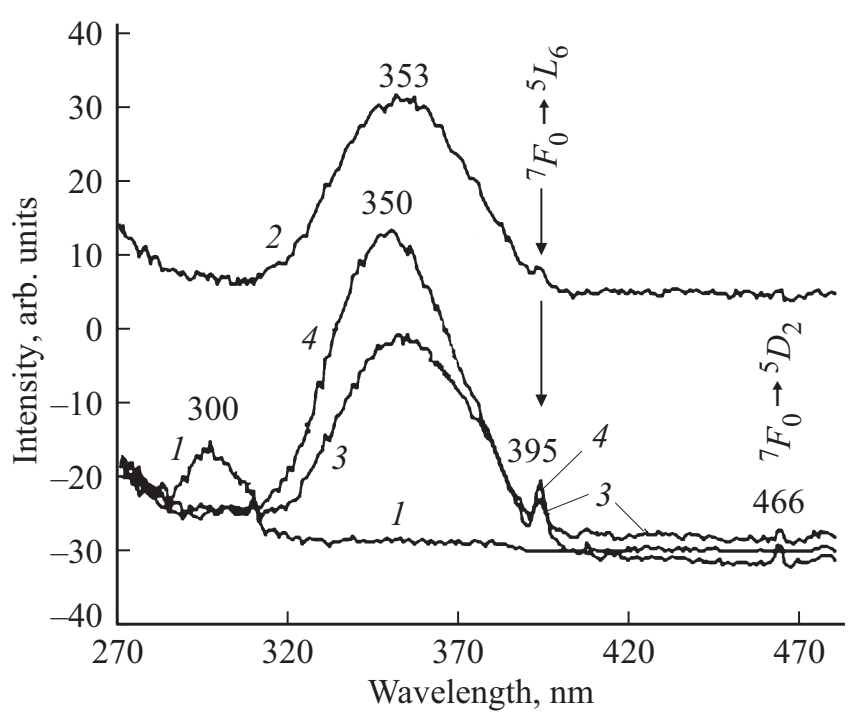

Рис. 7. Спектры возбуждения люминесценции композиций $\left(\lambda_{\mathrm{em}}=615 \mathrm{~nm}\right)$, положение максимумов, $\mathrm{nm} ;$ концентрация ионов $\mathrm{Eu}^{3+}, \mathrm{mol} / \mathrm{L}$ полимеризуемой смеси: 1 ПMМА/(Zn, Cu, Ag)S (300); 2 - ПMМА/(Zn, Cu, Ag)S: $\mathrm{Eu}^{3+}$ $\left(353 ; 1 \cdot 10^{-4}\right) ; 3-\Pi$ - $3 \mathrm{MMA} /(\mathrm{Zn}, \mathrm{Cu}, \mathrm{Ag}) \mathrm{S}: \mathrm{Eu}^{3+}$ 395,$\left.466 ; 5 \cdot 10^{-4}\right) ; 4-\Pi \mathrm{MMA} /(\mathrm{Zn}, \mathrm{Cu}, \mathrm{Ag}) \mathrm{S}: \mathrm{Eu}^{3+} \quad(350$, 395,$\left.466 ; 1 \cdot 10^{-3}\right) ; C_{\mathrm{Zn}}=1 \cdot 10^{-2} \mathrm{~mol} / \mathrm{L}$ реакционной смеси, $C_{\mathrm{Cu}}=C_{\mathrm{Ag}}=1 \cdot 10^{-3} \mathrm{~mol} / \mathrm{L}$ реакционной смеси. 
дополнительных дефектов на поверхности полупроводниковых частиц (рис. 7, спектры 2-4).

\section{4. Заключение}

При одновременном введении в метилметакрилат смеси трифторацетатов цинка, меди, серебра, европия и тиоацетамида, в качестве сульфидизатора, проведено легирование сульфида цинка. Термической полимеризацией ММА в блоке получены композиции ПММА/(Zn, $\mathrm{Cu}, \mathrm{Ag}) \mathrm{S}: \mathrm{Eu}^{3+}$, отличающиеся составом легирующих компонентов и содержанием ионов $\mathrm{Eu}^{3+}$. В спектрах композиций зарегистрированы широкие полосы фотолюминесценции, возникающие при рекомбинации зарядов на уровнях дефектов кристаллической структуры $\mathrm{ZnS}$, расположенных в запрещенной зоне полупроводника, и узкие полосы, связанные с ${ }^{5} D_{0} \rightarrow{ }^{7} F_{j}$ переходами электронов в ионах $\mathrm{Eu}^{3+}$. Возбуждение рекомбинационной люминесценции композиций связано с межзонным переходом электронов в $\mathrm{ZnS}$, а также с переходами электронов из валентной зоны на уровни, образованные дефектами кристаллической структуры $\mathrm{ZnS}$ в объеме и на поверхности частиц. Возбуждение узкополосной внутрицентровой фотолюминесценции происходит в результате собственных электронных переходов из основного ${ }^{7} F_{0}$ в возбужденные электронные состояния ионов $\mathrm{Eu}^{3+}$ и переноса энергии из зоны проводимости и с уровней дефектов структуры легированного $\mathrm{ZnS}$ на возбужденные уровни ионов $\mathrm{Eu}^{3+}$. На протекание данных процессов указывает наличие соответствующих полос в спектрах возбуждения, их перекрывание с полосами в оптических спектрах поглощения композиций и изменение их относительных интенсивностей при изменении состава композиций.

\section{Конфликт интересов}

Авторы заявляют, что у них нет конфликта интересов.

\section{Список литературы}

[1] О.Н. Казанкин, Л.Я. Марковский, И.А. Миронов, Ф.М. Пекерман, Л.Н. Петошина. Неорганические люминофоры. Химия, Л. (1975). 192 с.

[2] Н.К. Морозова, В.А. Кузнецов. Сульфид цинка. Получение и оптические свойства. Наука, М. (1987). 199 с.

[3] Р.Ф. Хайрутдинов. Успехи химии 67, 125 (1998).

[4] D. Denzler, M. Olschewski, K. Sattler. J. Appl. Phys. 84, 2841 (1998).

[5] В.Г. Клюев, Т.Л. Майорова, М. Фам Тхи Хаи, В.Н. Семенов. Конденсированные среды и межфазные границы 11, 58 (2009).

[6] С.В. Свечников, Л.В. Завьялова, Н.Н. Рощина, В.Е. Родионов, В.С. Хомченко, Л.И. Бережинский, И.В. Прокопенко, П.М. Литвин, Ю.В. Коломзаров, Ю.А. Цыркунов. ФТП 34, 1178 (2000).
[7] J. Planelles-Aragó, B. Juliàn-López, E. Cordoncillo, P. Escribano, F. Pellé, B. Viana, C. Sanchez. J. Mater. Chem, 18, 5193 (2008).

[8] Т.Н. Щерба, К.В. Лупандина, М.П. Жиленко, Г.П. Муравьева, Г.В. Эрлих, Г.В. Лисичкин. Изв. РАН. Сер. хим. 8, 1547 (2011).

[9] X. Gong, Z. Yang, G. Walters, R. Comin, Z. Ning, E. Beauregard, V. Adinolfi, O. Voznyy, E.H. Sargent. Nature Photon. 10, 253 (2016).

[10] С.В. Дайнеко, П.С. Самохвалов, Д. Лыпенко, Г.И. Носова, И.А. Березин, А.В. Якиманский, А.А. Чистяков, И. Набиев. Оптика и спектроскопия 122, 1, 17 (2017).

[11] М.А. Звайгзне, И.Л. Мартынов, В.А. Кривенков, П.С. Самохвалов, И.Р. Набиев. Оптика и спектроскопия 122, 1,76 (2017).

[12] G.S. Selopal, H. Zhao, X. Tong, D. Benetti, F. Navarro-Pardo, Yu. Zhou, D. Barba, F. Vidal, Z.M. Wang, F. Rosei. Adv. Funct. Mater. 27, 1701468 (2017).

[13] X. Tong, X.-T. Kong, C. Wang, Yu. Zhou, F. Navarro-Pardo, D. Barba, D. Ma, S. Sun, A.O. Govorov, H. Zhao, Z.M. Wang, F. Rosei. Adv. Sci. 5, 1800656 (2018).

[14] О.В. Овчинников, А.Н. Латышев, М.С. Смирнов. Конденсированные среды и межфазные границы 7, 413 (2005).

[15] J.K. Saluja, Y. Parganiha, N. Tiwari, V. Dubey, R. Tiwari, A. Prabhath. Optik. 127, 7958 (2016).

[16] Т.А. Кучакова, Г.В. Весна, В.А. Макара. ФТП 38, 1316 (2004).

[17] Ю.Ю. Бачериков, И.П. Ворона, С.В. Оптасюк, В.Е. Родионов, А.А. Стадник. ФТП 38, 1025 (2004).

[18] Н.К. Морозова, И.А. Каретников, Д.А. Мидерос, Е.М. Гаврищук, В.Б. Иконников. ФТП 40, 1185 (2006).

[19] М.Ф. Буланый, А.В. Коваленко, Б.А. Полежаев, Т.А. Прокофьев. ФТП 43, 745 (2009).

[20] К.А. Огурцов, В.В. Бахметьев, А.М. Абызов, М.Н. Цветкова, М.М. Сычев. Изв. СПбГТИ (ТУ) 7, 33, 13 (2010).

[21] К.А. Огурцов, М.М. Сычев, В.В. Бахметьев, В.Н. Коробко, А.И. Поняев, Ф.И. Высикайло, В.В. Беляев. Неорган. материалы. |bf52, 1188 (2016).

[22] T.B. Nasrallah, H. Dlala, M. Amlouk, S. Belgacem, J.C. Bernede. Synth. Met. 151, 225 (2005).

[23] С.И. Садовников, А.В. Чукин, А.А. Ремпель, А.И. Гусев. ФTT 58, 32 (2016).

[24] D. Karashanova, D. Nihtianova, K. Starbova, N. Starbov. Solid State Ionics 171, 269 (2004)

[25] V.B. Prabhune, N.S. Shinde, V.J. Fulari. Appl. Surf. Sci. 255, 1819 (2008).

[26] С.И. Садовников, А.А. Ремпель. Неорган. материалы. 51, 829 (2015).

[27] В.П. Смагин, Н.С. Еремина, А.Г. Скачков. Оптика и спектроскопия 124, 635 (2018).

[28] N. Jing-hua, H. Rui-nian, L. Wen-lian, L. Ming-tao, Yu Tianzhi. J. Phys. D 39, 2357 (2006).

[29] P. Mukherjee, C.M. Shade, A.M. Yingling, D.N. Lamont, D.H. Waldeck, S. Petoud. J. Phys. Chem. A 115, 4031 (2011).

[30] Kexin Zhang, Yaxin Yu, Shuqing Sun. Appl. Surf. Sci. 276, 333 (2013).

[31] А.В. Селищев, В.В. Павлищук. Теор. и эксперим. химия 51, 358 (2015).

[32] Zhanguo Liang, Jun $\mathrm{Mu}$, Lei Han, Hongquan Yu. J. Nanomater. Article ID 519303. (2015).

[33] Yongbo Wang, Xuhua Liang, Enzhou Liu, Xiaoyun Hu, Jun Fan. Nanotechnology 26, 375601 (2015). 
[34] Qian Chen, Jiahui Song, Chunyan Zhou, Qi Pang, Liya Zhou. Mater. Sci. Semiconductor Proc. 46, 53 (2016).

[35] Э.А. Сенокосов, И.Н. Один, М.В. Чукичев, В.М. Ишимов, И.В. Демиденко, Р.Р. Резванов. Неорган. материалы. 52, 1175 (2016).

[36] Н.С. Курочкин, А.В. Кацаба, С.А. Амброзевич, А.Г. Витухновский, А.А. Ващенко, П.Н. Тананаев. ФТП 51, 659 (2017).

[37] В.П. Смагин, Н.С. Еремина, А.А. Исаева, Ю.В. Ляхова. Неорган. материалы 53, 252 (2017).

[38] В.П. Смагин, Н.С. Еремина, М.С. Леонов. Неорган. материалы 54, 115 (2018).

[39] М.С. Смирнов, О.В. Овчинников, И.В. Тайдаков, С.А. Амброзевич, А.Г. Витухновский, А.И. Звягин, Г.К. Усков. Оптика и спектроскопия 125, 8, 240 (2018).

[40] S. Sadeghi, B.G. Kumar, R. Melikov. M.M. Aria, H.B. Jalali, S. Nizamoglu. Optica 5, 793 (2018).

[41] С.И. Садовников. Журн. неорган. химии. 64, 1116 (2019).

[42] E.M. Egorova, A.A. Revina. Colloid J. 64, 301 (2002).

[43] К.Ю. Пономарева, И.Д. Кособудский, Е.В. Третьяченко, Г.Ю. Юрков. Неорган. материалы 43, 1295 (2007).

[44] Е.Ю. Готовцева, А.А. Бирюков, В.А. Светличный. Изв. вузов. Физика 56, 32 (2013).

[45] В.П. Смагин, И.М. Фадин. Журн. неорган. хим. 58, 1212 (2013).

[46] В.П. Смагин, Д.А. Давыдов, Н.М. Унжакова, А.А. Бирюков. Журн. неорган. хим. 60, 1734 (2015).

[47] L. Bokatial, L. Rai. J. Fluoresc. 22, 505 (2012).

[48] I. Ahemen, D.K. De. Adv. Sci. Eng. Medicine 5, 1 (2013).

[49] S.C. Qu, W.H. Zhou, F.Q. Liu, N.F. Chen, Z.G. Wang, Huayong Pan, Dapeng Yu. Appl. Phys. Lett. 80, 3605 (2002).

[50] А.А. Бирюков, Т.И. Изаак, В.А. Светличный, Е.Ю. Готовцева. Изв. вузов. Физика 52, 16 (2009).

[51] В.П. Смагин, Н.С. Еремина, Д.А. Давыдов. Неорган. матерериалы 52, 664 (2016).

[52] В.П. Смагин, Н.С. Еремина, М.С. Леонов. ФТП 52, 891 (2018).

[53] М.А. Джафаров, Е.Ф. Насиров, Р.С. Джафарли. Неорган. материалы 53, 15 (2017).

[54] В.П. Смагин, А.А. Исаева, Н.С. Еремина, А.А. Бирюков. ЖПХ 88, 924 (2015).

[55] В.П. Смагин, Г.М. Мокроусов Физико-химические аспекты формирования и свойства оптически прозрачных металлсодержащих полимерных материалов. Изд-во Алтайского гос. ун-та, Барнаул. (2014), 258 c. http://elibrary.asu.ru/ xmlui/bitstream $/$ handle $/$ asu $/ 840 /$ read.7book? sequence $=1$

[56] А.А. Исаева, В.П. Смагин, В.А. Зяблицкая Журн. неорган. химии 64, 108 (2019).

[57] В.Н. Серова Оптические и другие материалы на основе прозрачных полимеров. Изд-во КГТУ, Казань (2010). $540 \mathrm{c}$.

[58] H. Ehrlich, T. Shcherba, M. Zhilenko, G. Lisichkin. Mater. Lett. 65, 107 (2011)

[59] Д.О. Сагдеев. Канд. дис. КНИИТУ, Казань (2019).

Редактор Т.Н. Василевская 